\title{
Teaching Societal Leadership Through Design: Case Study of a Cohort-Based Social Innovation Engineering Leadership Program
}

\author{
Albert Huynh and Mike Klassen \\ Institute for Leadership Education in Engineering \\ University of Toronto \\ albert.huynh@utoronto.ca
}

\begin{abstract}
Engineering students are well equipped with a technical background to become agents of social change. This paper highlights a co-curricular social innovation program that aims to foster that potential through team-based project-based learning. Key teaching methods are described, such as how students establish a vision, scope complex projects, effectively build teams, and leverage failure and iteration for learning. The program faces challenges maintaining student engagement and getting them to fully embrace learning through failure, but has had significant success in fostering self-reflection. It has also been successful in creating a structure whereby personal and leadership learning happen alongside design and project-oriented learning. There is opportunity for the teaching methods and structure of this program to be applied to other contexts in an effort to improve student team learning outcomes and find ways to integrate leadership learning into core technical and design courses.
\end{abstract}

Keywords: Social innovation, engineering leadership, society, teamwork, design, failure, project based learning, pedagogy

\section{BACKGROUND AND CONTEXT}

The Institute for Leadership Education in Engineering (ILead) was established in 2010 in the Faculty of Applied Science and Engineering at the University of Toronto with the vision statement of "Engineers leading change to build a better world." For most of its early history, the studentfacing impact of this vision statement was a collection of academic courses, workshops, and skills development programs around self and team leadership, with less of a focus around organizational and societal leadership [1]. In response to this gap, a co-curricular (non-credit) program called "The Game" was created in the Fall of 2014 to bring to life ILead's vision in a more direct way, with the intention of leveraging the talents and experiences of engineering students to engage in societal level change.

The Game, now finished its third year/cycle, is a 6month team project-based co-curricular cohort program for undergraduate and graduate engineering students running from October to March with 30-40 students per cycle. Regular meetings occur approximately every two weeks and include workshops, invited guest speakers, and facilitated work time. The program aims to develop capacity in multiple CEAB Graduate Attributes such the impact of engineering on society, individual and team work, and life-long learning [2]. The students enter with an aim to improve society and work over the course of the year to take steps towards realizing their vision through self-directed project-based learning. Financial awards are given at the end of the program to teams who demonstrate significant learning, progress, and potential for future growth through a project showcase.

Although aimed at engineering students, The Game is designed as an open-ended creative experience to allow for people to explore the idea of creating social change from many perspectives. In acknowledging that social systems are complex, the program encourages deviation from a single-pass design process and students are instead asked to leverage their engineering backgrounds in conjunction with critical inquiry to approach each project with an iterating perspective. As such, The Game is not explicitly an engineering design-project program (though it does draw on design principles), nor is it an entrepreneurial incubator program. Examples of themes in student projects include residential energy consumption, bridging understanding to Aboriginal experiences, the role of language proficiency in mental health treatment accessibility, food waste, and urban cycling safety.

In the first two iterations of the program, students struggled with the ambiguity of creating social change; they didn't know how to work effectively across different experiences, engage with real stakeholders, and scope a project that would have meaningful impact. Students tended to get stuck in "analysis paralysis," being 
overwhelmed by the complexity of the systems they were working in, and not knowing where to start. From a program design perspective, it was difficult to establish the idea that social change emerges, in part, from personal leadership and it felt like the leadership components of the program did not connect clearly with the project.

\section{CONCEPTUAL FRAMEWORKS}

To focus The Game more on what it means to create social change and less on producing a "product", the latest iteration was framed by an inquiry-based overarching horizon question". The question "How do I work with myself and others using effective tools and frameworks to create meaningful change?" was presented to students at the beginning of the program, with the intention that each experience they had would get them one step closer to an answer. The expectation was that in the final showcase, students would incorporate these dimensions in a presentation of what they learned about trying to create social change.

The Game aims to be a social innovation program. Although social innovation struggles to be defined, we situate it at the intersection of three other disciplines: design thinking [3], systems thinking [3], and leadership [4], while drawing on the approach of appreciative inquiry [5]. The Game also leverages practices from the $\mathrm{W}$-model for wicked problems [6], the design sprint [7], and the lean startup methodology [8]. Each of these frameworks is explicitly introduced in at least one workshop with the aim of integrating behaviours and practices based on these principles throughout.

\section{PEDAGOGICAL PRACTICES}

Given the wide range of learning objectives for the program, a number of different practices were employed in integrated ways to maximize the contact time with students. This paper highlights practices from three different areas based on their novelty and potential crossapplicability to similar programs and design projects in courses.

\subsection{Visioning and Project Scoping}

As an open-ended project-based program, students are responsible for selecting their own focus. To force them to distill their thinking, students apply for the program with a 144-character statement about their vision for a better world. They are then subsequently challenged to focus that statement down to a single user and a set of potential

\footnotetext{
${ }^{1}$ We thank Maria Vamvalis of The Critical Thinking Consortium for this concept and terminology.
}

action items to begin moving this vision forward. This process is iterated as students learn more about their area of interest, speak with stakeholders, and consult with external mentors.

This approach has several benefits for both individuals and the teams. Starting with a meaningful vision creates strong intrinsic motivation for students to work on their projects, which is important given the co-curricular nature of the experience. This process also forces them to consider project scope early on, helping navigate ambiguity and avoid decision paralysis. In addition, once project scope changes as a result of new information, having a vision lets students pivot while remaining true to their intended societal impact. From a team perspective, connecting over a shared vision can be a strong foundation from which to build shared purpose.

\subsection{Team Formation and Development}

Teams are formed based on a combination of shared vision and compatible values. These values are uncovered and made explicit in the first session of the program, where students are asked to engage in an active listening clinic. This listening clinic gives them the space to get to know one another on a deeper level by encouraging attentive and meaningful conversation. Active listening is a useful skill for being able to later draw out insights from stakeholders in the context of their social innovation work. Lastly, the practice of the active listening clinic helps students discover their personal values by sharing and curiously interrogating experiences where they have felt at their very best and at their very worst. Forming teams based on shared vision and a clear expression of values helps to foster relationships early on. Students are additionally asked to complete and share StrengthsFinder inventories [9] from the beginning of the program. This framing challenges students to think critically about team dynamics from the start.

From a team development perspective, these foundations are revisited as students learn to work with one another. Although individual values are discussed in the first session, several weeks later, students are asked to develop team norms based on their evolved understanding of each other's values. This avoids the trap of having teams create arbitrary team rules or team charters and it reinforces the importance of self-awareness as a leadership capacity. The StrengthsFinder results are brought back at the end of the program when students are asked to reflect on what their unique contributions have been in their team and what their teammates have contributed to the project and process of their learning. This helps to build appreciative inquiry and self-reflective practices, and helps students leverage their individual strengths better moving through and beyond the program. 
Finally, peer feedback throughout the program is facilitated through the use of a team effectiveness learning feedback system [10] which they are asked to contribute to midway through the program and again near the end of the program.

The combination of these practices as well as the requirement for students to present their personal and team leadership learning as part of their showcase presentations creates a cohesive thread of the importance of team building in the context of major projects.

\subsection{Failure, Iteration, and Learning}

A final theme is learning through fast failure, which is manifested in team formation, design/prototyping, and our focus on it as a topic during workshop discussions and presentations. Although the professional practice of engineering emphasizes avoiding failure through design to protect public safety, the focus in this program is not to undermine that, but rather to accelerate learning and impact when the opportunities to do so are available.

In team formation, students are given the opportunity to switch teams as many times as they see fit over the first several weeks of the program to get a feel for which dynamics work best for them. Explicit messaging that students should find appropriate fit (instead of switching for competency alone) is provided to mitigate apprehension about this process. From a design perspective, students are provided with prototyping challenges, even in light of limited knowledge, to try and push their assumptions on what works and what does not. This is inspired by the Wmodel, lean startup, and design sprint concepts. Forced to try things out frequently, students get an opportunity to practically assess what decisions they make with real data. During sessions where speakers come in (many of whom are practitioners of social innovation in various sectors), instead of asking them to talk about the success of their great projects, speakers are asked to share stories of the twists, turns, and failures of their projects that have led them to where they are now. This helps to paint a more realistic picture for the often slow and winding process of creating societal impact. When students are asked to present, the topic of learning through failure is also highlighted and incentivized, both in regular session check-ins where students are asked to share their recent roadblocks and challenges, and in their showcases. One of the final evaluation criteria for the program is demonstrated learning through failure.

\section{IMPACT AND STUDENT RESPONSE}

Given its co-curricular nature, there was some of attrition within the most recent cohort. 29 students completed the program, and 9 students dropped out sometime after the first session, often citing workload and other priorities as key factors. The average attendance at bi-weekly sessions was 23 students, dipping down to 15 for some sessions.

One related concern was the dissolution of one of the teams late into the program. The main issues were frustration with the inaccessibility of their chosen topic, the differing levels of commitment to the project, and the conflict resolution capability of the team.

Regarding the intended focus on fast iteration, some teams did not meaningfully engage with this experimentation until near the end of the program. Putting this in an institutional context, students in engineering programs may generally need more exposure to prototyping throughout the curriculum [11]; this has proven to be a barrier to embracing learning through failure in its full form.

When asked to numerically self-assess their growth through a retrospective pre-post survey, students overwhelmingly reported (1) being able to work better with others and (2) feeling empowered as social change agents. On the other hand, students reported feeling generally less confident in their ability to work with ambiguity. This could indicate that students had unrealistic expectations for how social change occurs, but it also highlights a space for better pedagogy on our part as program facilitators and designers.

In the post-program feedback survey, students expressed a great deal of personal growth around understanding how complex social innovation truly is, while simultaneously seeing themselves as being more capable of this type of work. Many spoke to the value of learning through adversity and that working with students from a variety of disciplinary backgrounds was unexpectedly enriching.

In observing their final showcase presentations, it was apparent that students had taken advantage of the space to be honest and reflective about their learning. Students spoke candidly about their failures and frustrations with project scoping, reconciling the views of different stakeholders, and prototyping and implementing ideas just as easily as they spoke about their new understanding of their personal strengths, the conflict management of their team, and their updated mental models of social innovation. More exciting still was how they were able to integrate the experiences of the technical project tasks with the reflections and insights that spun out from them. In engineering, where leadership and personal learning are often divorced from technical learning [12], students in this program deeply embraced the opportunity to do both in tandem. Several students also expressed interest in repeating the program for a second year, even though the current structure of the program does not provide a means for that to happen. 
By way of illustration, the winning team from this year's cohort focused on improving bicycle safety in Toronto. After briefly considering the option of a purely technical intervention, the team's first "prototype" was a proposal for a business certification program to recognize companies that had bicycle friendly amenities for their employees. Through contact with stakeholders, including several companies and local bicycle advocacy groups, they deemed the approach impractical. Once they reassessed their system of stakeholders, they pushed forward with an advocacy effort to the Ontario Ministry of Transportation asking for the inclusion of shoulder checks when opening car doors in the standard driver's examination. Reflecting on this experience, one student characterized it as "learning to let go of ideas...yet not being afraid to put work into ideas that may fail." Another one of the team members remarked that they most appreciated "learning about [their] own strengths and weaknesses" through the process, and yet another noted a better understanding that "meaningful change is created based on one's understanding and empathy of the group of people an issue affects." During their showcase presentation, they collectively expressed the importance of healthy group conflict in being able to generate a variety of ideas and perspectives for the project.

\section{IMPLICATIONS FOR FUTURE ITERATIONS}

It is important that we look into ways of supporting students' comfort with ambiguity without sacrificing the integrity of the inquiry-based learning process. A potential avenue for this may be to increase the presence of a coaching approach, where students are asked questions to help them clarify their own thinking. In team formation, in addition to facilitating self and team reflection, there could be a shift towards small project-oriented deliverables early on to help students get a more practical sense of what their motivation and team dynamics will be like moving through the program.

The deep value of integrated leadership and projectbased learning will be bolstered by more intentionally referring back to the horizon question whenever new project tasks are assigned. There will also need to be more intentional project tasks assigned early on that focus on prototyping with workshop material built around the necessity for students to engage in this process.

\section{TRANSFERABILITY OF TEACHING PRACTICES}

The pedagogical foundation for The Game is social constructivism [13]. When applied to project-based learning, particularly in highly complex and ambiguous situations, this approach of providing a point of inquiry and allowing students to socially leverage their skills and knowledge to make meaning is an efficient means of creating relevant context and strong buy-in from students. This approach is applicable in any type of course by using the frame of curiosity to pose questions to students to investigate at the start of each module or concept.

In design courses, instructors can ask students to think about their intended societal impact from the outset of a project, which can in turn help students to be flexible when developing solutions. It also gives context for the work that they are trying to do. Instead of focusing just on the "what" and "how," understanding the impact or "why" through something akin to a vision can help to increase motivation. Also, allowing students to select their own projects, as long as they are properly guided and refined through a structured process, can help to improve commitment to the work.

A transferable practice for team formation is to allow students to find their teammates through an iterative process comparing the skills, values, and working styles of others to create high functioning teams. From a team building perspective, students can be introduced to the concept of leveraging differences early in a learning experience. By focusing on what makes each student unique (via self-reflection), they are more likely to take advantage of the specific dynamics and composition of members of their team, instead of assuming that all teammates need to serve the same functions. Asking students to revisit their team reflections in the context of the actual contributions and outcomes of the project they are working on can integrate team learning with check-ins on project progress.

From a learning assessment standpoint (particularly in course projects) we can consider evaluating the learning process as much as the final products. Although there are always key learning outcomes for students to demonstrate, having a mix of outputs (in the form of a written reflection, presentation, or reflective journal) builds the bridge between the technical requirements of a course and the personal leadership learning they acquire.

\section{CONCLUSION}

Although there is still significant room for growth, in its most recent iteration The Game serves as a case for inquiry-based, project-based learning. In the program, personal and leadership concepts are developed through the experiences of accomplishing project tasks and assessments privilege the process of learning over the product. We believe these principles and practices can be adapted to other contexts, including for-credit design courses, to enrich student learning outcomes and develop engineers who can build a better world. 


\section{References}

[1] Douglas Reeve, Greg Evans, Annie Simpson, Robin Sacks, Estelle Oliva-Fisher, Cindy Rottmann, and Patricia Sheridan, "Curricular and co-curricular leadership learning for engineering students," Collected Essays on Learning and Teaching, vol. 8, pp. 1-16, 2015.

[2] Canadian Engineering Accreditation Board, Accreditation Criteria and Procedures. Ottawa, ON: Canadian Engineering Accreditation Board (CEAB), 2016, 121 pp. Available as of January 19, 2017 from https://engineerscanada.ca/sites/default/files/AccreditationCriteria-Procedures-2016-final.pdf

[3] Geoff Mulgan, "The process of social innovation," innovations, vol. 1, no. 2 pp. 145-162, June. 2006.

[4] Cindy Rottmann, Robin Sacks, and Douglas Reeve, "Engineering leadership: Grounding leadership theory in engineers' professional identities," Leadership, vol. 11, no. 3, pp. 351-373, 2015.

[5] David Cooperrider and Suresh Srivastva. "Appreciative inquiry in organizational life," Research in organizational change and development, pp. 129-169, 1987.

[6] Christopher Moraes, Stefanie Blain-Moraes, and Rob Gorbet, "Teaching engineering students to design solutions to wicked problems," presented at the 2015 CEEA Annual Conference, Hamilton, ON, 2015.

[7] Jake Knapp, John Zeratsky, and Braden Kowitz. Sprint: How to Solve Big Problems and Test New Ideas in Just Five Days. New York, NY: Simon and Schuster, 2016, $288 \mathrm{pp}$.
[8] Michel Gelobter. Lean Startups for Social Change: The Revolutionary Path to Big Impact. Oakland, CA: BerrettKoehler Publishers, 2015, 216 pp.

[9] Tom Rath. StrengthsFinder 2.0. New York, NY: Gallup Press, 2007, 175 pp.

[10] Patricia Kristine Sheridan, Lobna El Gammal, Jenni Phillips, Greg Evans, and Douglas Reeve, "A Teameffectiveness Inventory for Guided Reflection and Feedback," presented at the 2013 ASEE Annual Conference \& Exposition, Atlanta, GA, 2013.Patricia TELS reference

[11] Aaron Hutchins. "Why don't future engineers learn realworld skills in school?" Maclean's, September 26, 2015. Available as of May 2, 2017 from http://www.macleans.ca/education/university/why-dontfuture-engineers-learn-real-world-skills-in-school/

[12] Domenico Grasso and Melody Burkins, Holistic Engineering Education: Beyond Technology. New York, NY: Springer Science \& Business Media, 2010, 301 pp.

[13] Katherine Powell and Cody Kalina. "Cognitive and Social Constructivism: Developing Tools for an Effective Classroom." Education, vol. 130, no. 2, pp. 241-250. 2009. 